rily assumes that the cholera poison is always swallowed, and never inhaled; but I would ask Mr. Simon, and those who agree with him, to refer to any analogous poison remaining in contact with the alimentary canal, without entering the blood as an essential condition of its poisonous operation, and giving rise to analogous symptoms by a merely nervous sympathy. Mr. Simon does not deny that the blood is poisoned during cholera. In proof that it is so poisoned, he refers to numerous recorded cases in which the intrauterine offspring has been killed by the cholera poison conveyed to it, as Mr. Simon admits, through the maternal blood, and exciting the characteristic rice-water discharges into the alimentary canal. But he asks, "Is there any reason to suppose that the cholera contagium in the mother's blood was not a secondary product of disease-was not let into her circulation from the ferment-seething interior of her bowels?' I would ask, Is there any reason to suppose that there exists such an essential difference between the primary poison which conveys the disease to the mother, and the secondary product which imparts the same disease to her offspring, that, while one is absolutely excluded from the maternal circulation, the other is freely admitted? But the difficulty does not end here. It is manifest that, before the poison can act upon the alimentary canal of the foetus, not only must it have entered the blood of the mother, but it must also have passed through the circulation of her offspring. If it were true, as Mr. Simon believes, that "cholera begins as a bowel-disease, producible by direct contagion, without even the passive intervention of the blood," then the foetus in utero would be absolutely safe from the operation of the poison, which could not, under the assumed conditions, be brought into contact with its alimentary canal. As the intrauterine offspring may die of cholera, so may it die of small-pox, conveyed to it, like cholera, by the maternal blood. What now would be thought of this question, if it were seriously put? Is there any reason to suppose that the small-pox virus in the mother's blood was not a secondary product of disease - was not "let into her circulation from the ferment-seething" surface of her skin? Mr. Simon, by his reference to cases of intrauterine chotera, has afforded valuable confirmatory evidence in favour of the proposition that the cholera poison, in whatever way it enters the system, whether with the air through the lungs, or with the food or water through the alimentary canal, is absorbed into the blood before it gives rise to its characteristic effects.

\section{THERMAL VALUE OF FOOD.*}

By WILLIAM H. O'LEARY,

and Physiology, Ledwich School of Medicine; Surgeon to

\section{Locturer on Anatomy and Physiology, Ledwich School of
St. Vincent's Hospital, Dublin; etc}

THE object of the paper I have the honour of bringing before the Association, is to demonstrate that which must appear patent to every mind from a purely physical point of view - that the food ingested and chemically acted upon in the system (blood ?) is perfectly adequate to account for the various opera required for its ordinary and extraordinary wants. This subject I propose to consider under two heads. I. The food egested in a given time, and an ascertainment of its thermal value. 2. The disposal of its thermal value between the heat consumed in calorifying purposes, and as a mechanical agent.

My experiments extended over a period of six consecutive days, and were performed on myself with a view to obtaining the greater accuracy of result: The first difficulty I experienced was in endeavouring to obtain accurate analyses of the food ingested; but I have spared no labour in collecting the most reliable information on this point.

In the first item of food, eggs, I have availed myself of Gobler's analysis of the yolk. I found great difficulty in obtaining an accurate analysis of the white; but, for this, I have taken Lehmann's results. For butter, I have taken Broun's analysis. Potatoes I had weighed after having been cooked and roasted, containing at time of ingestion about 50 per cent. of water. Milk I used at specific gravity of 1038; in this I have accepted Vernois and Becquerel's results; and, in doing so, Professor Cameron informs me, I am justified, although he differs slightly from them. For the quantity of water in meats, raw and cooked, as well as the water of panification in bread, also the water in vegetables used by me during my experiments, I have availed myself of the results of the Rev. Professor Haughton's investigations, as quoted in the Dublin Quarterly Medical Fournal, August 1859-60.

I deem it unnecessary to give each day's food separately. The following is taken from one of the six days, and will suffice. June 20 th. Eggs, $3 \frac{1}{6}$ oz. ; well dried toast, white bread, 2 oz.; butter, $3 \frac{1}{1}$ oz.; sugar,

\footnotetext{
Medical in the Physiological Section before the Annual Meeting of the British Medical Association in Dublin, August 1867.
}

white, 2 oz.; milk, fl. $4 \mathrm{t}$ oz. ; beef, muscle, 9 oz.; fat of ditto, 1 oz. ; white bread, one day old, $4 \frac{1}{1}$ oz.; bitter ale, fi. 22 oz.; brandy, fl. 2 ; oz.; water, 6 oz.; tea, f. $25 \mathrm{oz}$. The six days' experiment gave an average of, by analysis, carbon 2758.6 grains, hydrogen 405.9 grains, nitrogen 216.2 grains, oxygen 515.2 grains, alcohol 1979.4 grains. The proportion of alcohol in this table looks suspiciously large; but this is accounted for by the fact that, instead of calculating the thermal value of starch and sugar simply by their elements, I ascertained what amount of alcohol they would produce if converted into it, and allowed in my calculations the thermal value which would be rendered by its complete oxidation in the blood. This latter course $I$ have adopted rather than the former, not without due consideration or anticipating objections which may be raised against it.

The determination of the thermal value of the carbon, hydrogen, nitrogen, and oxygen, ingested, is based on the following considerations. The nitrogen, I have presupposed, enters into the formation of urea without necessarily raising the question, whether it is derived exclusively from the tissues, or the food, or both.

To the nitrogen I have assigned quantities" of carbon, hydrogen, and oxygen, in the proportion to form urea; but the carbon entering into combination with it exists in the proportion of $\mathrm{C}^{2} \mathrm{~N}$ (cyanogen); which again has oxygen united with it in the proportion of $\mathrm{C}^{2} \mathrm{NO}$ (cyanic acid); which latter union gives a thermal value equal to the quantity of carbon in combination with it. I, therefore, give to the carbon uniting with nitrogen to form urea such thermal value as if it had been completely oxidised, producing $\mathrm{CO}^{2}$, and exhaled by lungs or skin. To the hydrogen entering into combination with the compound radicle, $I$ do not assign a thermal value; but $I$ am not at all confident that $I$ am justified
in doing so.

By the following table, we can easily calculate the number of grains of carbon, hydrogen, and oxygen, united with the nitroge' ingested; viz., 216 grains to form urea.

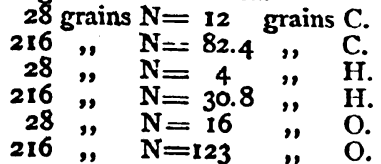

The following table shows the number of grains of carbon, hydrogen, and oxygen available, after disposal of such as unite with nitrogen to form urea.

Total quantity ingested Total excreted as Total quantity remaining
daily in grains.
urea in grains.
C. 2758.6
.......
C 82.4
H 30.8
N 216.2
N 216.2
O 515.2
O 123.0
for further disposal.
C 2758.6
..... II 375.1
...... N nil.
O 393.3

The oxygen ingested, I have assumed, had been already combined with hydrogen and carbon of the food, in the proportion to form water and carbonic acid, in perhaps a rather empirical manner; viz, equal parts of hydrogen and carbon, assigning to them, therefore, no thermal value; but not without some misgiving as to the accuracy of doing so; looking upon the question as a truly important one, not more to the present issue than in a chemical point of view.

The following table shows the number of grains of hydrogen and carbon already in combination with oxygen in the food, which may be calculated thus :

393 grains $\mathrm{O}=49$ equivalents.

49 equivalents $\{24.5$ equivalents $O=24.5$ grains $H$.

This number of grains of cäbon and hydrogen are not available, therefore, as a thermal agent, and must be deducted.
Available after loss by
urea in grains.
$\mathbf{C}+\mathbf{H}$ in union with
$O$ in food.
C 2758.6
H 375.1
.......
C 73.0
H 24.5
O nil.
$\cdots \cdot$
Total available for thermal uses.
C 2685.6
O 393.3
.......
.......
H 350.6

After calculating the number of grains of carbon and hydrogen which enter into the formation of urea, and the quantity already in combination with oxygen in the food, we have a total residuum of 2685.6 grains of carbon, 350.6 grains of hydrogen, and 1979.4 grains of alcohol, available for oxidation, producing thermal results. The value of these $I$ will now reduce to a tangible form; viz., what physicists term thermal units. Each thermal unit represents that amount of heat which is capable of raising one pound of water through one degrec, either centigrade or Fahrenheit, and equally represents mechanical force. Thus, the heat which is capable of raising one pound of water through one degree centigrade is capable of raising $1390 \mathrm{lbs}$. one foot high, or one de- 
gree Fahrenheit 772 lbs. one foot high; in physical language, 772 footlbe. Hence, in speaking of thermal units, each is understood to represent a definite quantity of heat or of force, these being convertible terms.

For the determination of the force or heat available to the system ingesting the above quantities of carbon, hydrogen, and alcohol, I have availed myself of MM. Faber and Silvermann's determinations of their combustion heats, agreeing as they do so closely with those of Dulong, etc. These physicists find that one pound of diamond (pure carbon) perfectly oxidised, producing carbonic acid, gives out in burning heat equivalent to raise $\mathbf{7 7 0 0}$ lbs. of water one degree centigrade, or $\mathbf{7 7 0 0}$ thermal units. One pound of hydrogen oxidised, producing water, gives heat equal to 34,500 thermal units. One pound of alcohol oxidised produced heat equal to 7180 thermal units.

Upon these data we can easily calculate the thermal value or, in other words, heat- and force-producing power of the carbon, hydrogen, and alcohol, at our disposal.

If 7000 grains of $C=7700$ thermal units, 2685.6 grains $C=2953.5$ thermal units.

If 7000 grains of $\mathrm{H}=34,500$ thermal units, 350.6 grains $H=1727.9$ therma units

If 7000 grains of alcohol $=7180$ thermal units, 1979.4 grains of alcohol $=2029.8$ thermal units. Giving as a total result : C 2953.5) H 1727.9$\} 6711.2$ thermal units. Alcohol, 2029.8

Therefore, my six consecutive days' experiment upon myself led to this conclusion, that the food ingested daily produced a chemical result, exhibited as heat and force, equal to 6711.2 thermal units; or a heat equal to the raising of $6711.2 \mathrm{lbs}$. of water through one degree centigrade; or on amount of force equal to $6711.2 \times 1390$ foot-lbs.; which heat or force I shall dispose of in my next paper, in accounting for the work done and the portion used for calorifying purposes.

The following is an accurate account of the fluids ingested and egested during the time of my investigations; and, as they have an important bearing on the results I arrive at, I quote them.

The total amount of water ingested, as fluid and in food, during the six days, was .................................................

Total egested by kidneys. Do. do. freces .............................. 16.8 oz. Do. do. sputa ............................ $6.0 \mathrm{oz}$.

256.802 .

Which gives an average daily surplus available for ex-

halation by skin and lungs ......................... 26.21 oz

But in the oxidation of the hydrogen of the food we have water produced as fullows :

Hydrogen in food ....................405.3 grs.

Less do. in urea not forming water $30.8 \mathrm{grs}$.

$374.5 \mathrm{grs}$.

$\mathbf{H}$ in alcohol completely oxidised...258.

$632.5 \mathrm{gr} .=13$. $^{\text {. }}$ o oz. water

Total quantity available daily for exhalation by skin and lungs....

experiment in the following manner. I enclosed determined by direct air-tight gutta-percha covering, with a number of small pieces of sponge enclosed, in contact with my skin, asccrtaining weight of bag and sponges before and after experiment; the length of time my arm was in the bag on no occasion was less than 12 hours. I then ascertained the superficial extent of the skin acted upon, and the entire superficies of my body, the result of the experiment gives me as the total exhalation from the tegumentary surface

Exhalation from the lungs (by difference) $20.5 \mathrm{oz}$. $18.7 \mathrm{oz}$

Total exhalation for 24 hours ...................... 39.207.

Total quantity of urine excreted by kidneys, 6 days, 234 oz., giving an average of $39 \mathrm{oz}$. per diem, having a specific gravity of 1017.5; giving of urea, 405.6 grains.

Nitrogen ingested daily, 216 grains; urea, 496.6 grains. There was, therefore, a quantity of nitrogen equal to 91 grains of urea, excreted by the rectum, and as salts; the lungs, I believe, not at all participating in
its elimination.

\section{[To be continued.]}

\section{OBSTETRIC MEMORANDA.}

[UNDER this head, we shall, from time to time, as materials come to hand from correspondents, publish records of cases remarkable in themselves, or illustrating points of interest in obstetric practice, therapeutic or manipulative. We shall probably in this way preserve from oblivion the notes of very many useful and instructive occurrences in private practice; for the great obstetric experience is that-for the most part hitherto unwritten - of the great body of general practitioners throughout Great Britain. We will only ask those who may forward cases for record, to relate them with the utmost brevity, and equally to condense any appended remarks.]

\section{OCCLUDED VAGINA COMPLICATTNG LABOUR.}

By Philit C. De la Garde, F.R.C.S., Exeter.

SOME time since $I$ received a note from a surgeon of my acquaintance, desiring me to meet him at a house which he named, about sixteen miles from Exeter, and to bring my midwifery instruments, for his patient was in hard labour, but could not be delivered, as she had no vagina. I found a strong hale woman, between 30 and 40 years of age. She had had severe and frequent pains for more than thirty-six hours. She was not at all exhausted, but was full of life and courage. She appeared unconscious of danger; and I only render justice in saying that she made no difficulty from first to last. Her own account was that, eight years before, she had, after a very protracted labour, been delivered with instruments. There had probably been laceration; there must have been sloughing. She had menstruated regularly since; and had lived with her husband on terms which satisfied both.

I found the labia, nymphæ, and clitoris, quite normal; but the vagina was closed, by adhesion of its sides, for two inches at least. This mass of cicatrix was faced by the adjacent lining of the labia, which extended across and sealed it up, except at the lower part, where a fistulous orifice would just allow an urethral bougie (No. 6) to be wormed through. This orifice was not found without difficulty; and, for three inches, the bougie had to be manouvred through a narrow and tortuous passage, after which it went on without obstruction. About six inches of the bougie had been introduced; I drew it out much twisted. The last four inches were daubed with fæces, but she was not awrare of this communication with the rectum. The meatus urinarius was bruised and stretched by an attempt to dilate it, made, for some motive not explained to me, by another surgeon who had been consulted the day before.

I had to choose between the Cresarean section and opening up a passage through the pelvis. I preferred the latter. I drew off a quantity of foul urine, which blackened the catheter. Then I introduced a curved hernia director (a straight director would not pass) for about two inches (the thickness of the occluding mass), and, with a probe-pointed bistoury, cut right and left, avoiding the urethra, bladder, and rectum. I could then introduce my finger into the os tincre, and, although the membranes were unusually thick and tough, felt the head high up in the pelvis. The os might be about an inch in diameter. The edge was hard; but I waited, hoping it might yield, and that the head would then tear its way until it approached the perinzum, which could be more easily dealt with. The pains were strong; but no progress was made in the next hour and a half. I again cut right and left, making the wound two inches and a half wide. Venous hrmorrhage followed, but less than I expected. I had provided tincture of matico and tincture of muriate of iron, but neither of these styptics was required. I should certainly have used the ether-spray, but no apparatus was at hand. I found the os tincre involved on the left side in cicatrix. I divided its edge where so attached for about half an inch. I waited an hour, hoping the head would descend. It advanced a little, and then stopped. Then I forcibly pushed my whole hand up through the pelvis, rending the interlacing bands of cicatrix. The os uteri was well dilated, and the head protruding into it. I ruptured the membranes, and the forehead presented. It was not possible to apply the forceps, but I lodged a vectis on the chin. During more than an hour I drew powerfully with every pain; but I made no progress. At length, the woman began to fail; her pulse became feeble, and her skin cold and damp. Should I make one more effort to save the child ? Could I not turn it ? Perhaps I might; but I knew that I could never extricate its head in time to save its life, and that I should add greatly to the mother's peril by the attempt. could not even ascertain the dimensions of the upper pelvic aperture; but the head was impacted within its brim, and the history of the first labour made its narrowness presumable. I, therefore, perforated the head, and broke up the cerebrum. This was done while the vectis had remained 